\title{
A ZOO(PO)ÉTICA DE AGUALUSA
}

\author{
Luana Barossi \\ Universidade de São Paulo \\ São Paulo, BR
}

\section{Resumo:}

As obras $O$ vendedor de Passados e Teoria geral do Esquecimento, de José Eduardo Agualusa, apresentam personagens animais e relações entre humanos e animais não-humanos que contrariam as teorias filosóficas e interpretativas tradicionais, possibilitando leituras que rompem com noções preestabelecidas pelas teorias de matriz estruturalista e cartesiana. Como sugeriu Donna Haraway, o ciborgue aparece como mito precisamente onde a fronteira entre o humano e o animal é transgredida, como se passa nas zonas de indiscernibilidade das personagens de Agualusa, que estabelecem uma (po)ética animal e, portanto, ciborgue. Este artigo tem como intuito trazer à discussão algumas dessas ocorrências animais - ou animots - nas duas obras em questão.

Palavras-chave: José Eduardo Agualusa; animot; devir-animal, pós-humano

\section{AGUALUSA'S ZOO(PO)ETHICS}

\begin{abstract}
:
The works The Book of Chameleons and General Theory of Oblivion, by José Eduardo Agualusa, present animal characters and relations between humans and non-human animals that go against traditional philosophical and interpretative theories, allowing perspectives that break with the notions created by the Cartesian and structuralist matrix theories. Donna Haraway suggested that the cyborg appears in myth precisely where the boundary between human and animal is transgressed, just as the indiscernibility lines created by Agualusa's characters, which establish an animal (po)ethics and, therefore, cyborg. This paper aims to discuss some of these animal - or animots - occurences in Agualusa's works.
\end{abstract}

Keywords: José Eduardo Agualusa; animot; becoming-animal, posthuman

\section{[...] não como a borboleta a romper a pupa, mas como uma lagarta a irromper de uma borboleta.}

(José Eduardo Agualusa)

As possibilidades de relações entre humanos e animais aparecem com frequência em narrativas literárias. A abordagem de leitura para essas ocorrências pode variar muito, seguindo por vezes os pressupostos das teorias da interpretação, mas, outras vezes, uma lógica inversa, que não toma como base as certezas como definidas por nossa tradição epistêmica de matriz cartesiana. Se tomarmos o modelo realista-naturalista de animalização do humano como uma maneira de representar um afastamento da técnica por um grupo ou classe social, podemos inferir que se considera que o animal não-humano não deteria, sob essa perspectiva, o poder da técnica, de forma que as comparações ou metáforas exigem do leitor uma operação cognitiva que pressupõe uma superioridade humana. As obras do angolano José Eduardo Agualusa, em contrapartida, quando apresentam relações entre humanos e animais não-humanos, fazem-no tomando como mecanismo as zonas de indiscernibilidade, sem carregá-los (personagens humanos, animais e híbridos) de uma lógica binária e maniqueísta. 
O vendedor de passados, publicado pela primeira vez em 2004, conta a história de Félix Ventura, um albino que ganha a vida como genealogista, ou, em outras palavras, oferece a quem precisa "um passado melhor". Seu companheiro de apartamento é uma osga, nomeada por Félix de Eulálio. A osga narra a história sob seu ponto de vista, tendo uma perspectiva interna do apartamento de Félix. Narra o que vê e ouve no apartamento, bem como explicita as metamorfoses que a realidade sofre no processo de criação do genealogista, pois este assume: "aquilo que eu faço é uma forma avançada de literatura. Também eu crio enredos, invento personagens, mas em vez de os deixar presos dentro de um livro dou-lhes vida, atiro-os para a realidade" (AGUALUSA, 2015, p. 75). Contudo, um homem solicita que Félix crie para ele não apenas um passado melhor, mas uma nova identidade. Tal pedido faz com que o albino construa, então, a identidade de José Buchmann, um fotógrafo de guerra, de maneira tão verossímil, que assume o caráter de real. Outra personagem importante é a também fotógrafa - ou, como ela prefere ser chamada, colecionadora de luzes - Ângela Lúcia.

A obra Teoria geral do esquecimento, do mesmo autor, foi publicada em 2012. O romance se passa em Luanda, num período que se estende das guerras de independência à contemporaneidade. A personagem principal é Ludovica, de codinome Ludo, uma portuguesa de Aveiro que vive por muitos anos trancada em um apartamento no último andar do chamado "Prédio dos Invejados", na zona nobre da capital angolana. Assim como Félix Ventura, tem como companheiro de apartamento um animal, mais especificamente o cão nomeado por ela de Fantasma, um pastor alemão que, assim como o personagem d'O Vendedor de Passados, é albino. Ludo tem acesso a uma biblioteca gigantesca que houvera sido cultivada por seu cunhado Orlando, de modo que seu "fora" se constitui pelas narrativas desses livros. Sua realidade é construída por meio da escrita, de diários e de narrativas poéticas rabiscadas a carvão nas paredes do apartamento. $\mathrm{O}$ espaço fechado do apartamento, por sua vez, torna-se sua concha protetora, em substituição ao seu casco de tartaruga arrancado, sensação que tinha desde a infância: "sentia-se, ao sair de casa, frágil e vulnerável, como uma tartaruga a quem tivessem arrancado a carapaça" (AGUALUSA, 2012, p. 11). Fundindo-se com o ambiente, ela se produz por meio das narrativas que esboça nas paredes.

Ambos os romances explicitam relações entre humanos e animais e até mesmo desconstruções da roupagem e das codificações que definiriam epistemologicamente o que é o humano de maneira a produzir sequências narrativas que, se lidas sob a perspectiva do devir, podem metamorfosear as próprias concepções de mundo do leitor.

Alocado historicamente na posição de "o outro" por excelência em relação ao humano - que seria, por sua vez, o centro do universo, capaz de obter o conhecimento racional e científico sobre todas as coisas - o animal não-humano é considerado, por parte de algumas teorias oriundas da tradição racionalista de matriz cartesiana, um ser irracional e sem linguagem.

Heidegger (1995) leva a reflexão adiante, ao propor que nem a racionalidade nem a animalidade delimitariam o que é o humano, pois este não é definido por um "o que é", mas por um "como é". Para o filósofo, um ser humano não deve então ser entendido apenas como um corpo (animal) mais alguma coisa (mente). Contudo, apesar de criticar a classificação do humano como animal racional, Heidegger discorre que a essência da animalidade, além da ausência de linguagem e da destinação ao mutismo, é o que ele chamou de Benommenheit, vocábulo traduzido como vertigem, embrutecimento, atordoamento, uma vez que o animal não teria acesso à sua coisa em si, ao "enquanto tal" do que é. A ação e o mundo animal seriam empobrecidos (Weltarm), enquanto as práticas humanas seriam sempre significativas e formativas (Weltbildend). $\mathrm{O}$ autor elabora que o Homem, distintamente da planta ou do animal, é o ser vivo capaz do discurso. Esta afirmação não significaria apenas que além de suas outras faculdades o Homem também tem a faculdade do discurso. Significa dizer que somente o discurso possibilita ao homem ser o ser vivo que é.

Para Walter Benjamin (2011), o humano detém a capacidade inata de nomear, enquanto o animal é melancólico por natureza, pois sofre de um sentimento sem-nome. Ele é nomeado e ao se encontrar privado de linguagem não pode se nomear. Benjamin ainda 
completa, dizendo que esse empobrecimento e essa privação corresponderiam ao grande sofrimento da natureza, que não diz respeito somente à privação de linguagem e ao mutismo, mas também a uma espécie de queixa, uma queixa muda.

A lei da falta, atribuída aos humanos por algumas teorias filosóficas e psicanalíticas, aplicar-se-ia aos animais como a falta de uma razão nos moldes dos desdobramentos dos pensamentos cartesiano, heideggeriano e benjaminiano. $\mathrm{O}$ animal sofreria, nessa perspectiva, da falta por não ter a capacidade de pensar racionalmente como o humano e nem de nomear-se, estando destinado ao embrutecimento, ao mutismo e à melancolia advinda dessa condição.

No entanto, os filósofos Gilles Deleuze, Felix Guattari e Jacques Derrida convidam-nos a uma paralaxe de pensamento. Os primeiros a partir do conceito de devir animal, e Derrida, por sua reflexão anticartesiana e antiestruturalista L'animal que donc je suis, traduzida ao português como "O animal que logo sou (a seguir)". Isso porque o verbo conjugado "je suis" pode significar ao mesmo tempo "eu sou" e "eu sigo".

Deleuze e Guattari desenvolvem o conceito de devir-animal, no qual colocam que o ser que cria linhas de fuga às codificações humanas pode passar por sequências animais inauditas, que não se contentam com a imitação, pois a imitação ficaria limitada à recognição, e, de acordo com os filósofos, "[d]e todos os movimentos, mesmo finitos, do pensamento, a forma da recognição é certamente a que vai o menos longe, a mais pobre e a mais infantil" (2001, p. 181).

Está tudo aí: um devir-animal que não se contenta em passar pela semelhança, para o qual a semelhança, ao contrário, seria um obstáculo ou uma parada; um devir-molecular, com a proliferação dos ratos, a matilha, que mina as grandes potências molares, família, profissão, conjugalidade. (DELEUZE e GUATTARI, 2012, p. 12)

Derrida, em contraposição tanto ao pensamento cartesiano quanto ao heideggeriano e benjaminiano, implicou que "o pensamento do animal, se pensamento houver, cabe à poesia" (p. 22). Quando Octavio Paz escreve que a poesia não está no metro ou na rima, que são mecanismos retóricos da forma, mas que "um quadro, uma escultura, uma dança são, à sua maneira, poemas" (p. 26), ele nos dá abertura para tratar a obra de Agualusa como uma poética, embora escrita em prosa. Uma poética animal, se colocarmos no coro as palavras de Derrida.

Donna Haraway (2009) escreveu que um ciborgue é um "híbrido de máquina e organismo, uma criatura de realidade social e também uma criatura de ficção" (p. 36). Carne e elemento técnico não representam a natureza e a cultura, respectivamente, como proporiam os adeptos das teorias tradicionais, mas se constroem mutuamente através de zonas de indiscernibilidade. Haraway afirma que o "ciborgue aparece como mito precisamente onde a fronteira entre o humano $\mathrm{e}$ o animal é transgredida. Longe de assinalar uma barreira entre as pessoas e os outros seres vivos, os ciborgues assinalam um perturbador e prazerosamente estreito acoplamento entre eles" (p. 41). A autora propôs que a escrita é, preeminentemente, a tecnologia dos ciborgues (p. 88). Propomos, aqui, uma extensão deste corpo "escrito" para a produção narrativa. Como a fronteira entre a carne e o elemento técnico é uma superfície borrada, a narrativa é também a carne, a carne é também a narrativa.

$O$ vendedor de passados tem como narrador-personagem nada menos que uma lagartixa, uma osga-tigre, que, nas palavras do personagem Félix Ventura, tem a capacidade de soltar estranhos sons que nos fazem acreditar serem gargalhadas humanas. O sorriso do réptil, no entanto, que poderia em um primeiro momento ser relacionado ao sorriso que o personagem João Pedroso viu em um lagarto de dois rabos na obra de João Ubaldo Ribeiro (1989), é um sorriso real, uma vez que a osga-tigre, apesar de não falar como os animais da ilha do Dr. Moreau (WELLS, 2012), pensa e narra a história, ao mesmo tempo em que expõe sua aflição de não ser vista. Ela narra: "Ninguém me vê. Nem sequer os japoneses, em grupos, com máquinas de filmar, e olhos estreitos, atentos a tudo" (p. 31). Lembrava-se, no entanto, de sua vida passada, quando ainda humana tampouco era vista: "Quando tinha ainda forma humana, acontecia-me o mesmo com certa frequência. Lembro-me de 
acordar depois com a boca amarga e o coração cheio de angústia" (p. 31).

Essa lembrança dos tempos em que era humano coloca em pauta a improbabilidade dos eventos da realidade, desenvolvida por Agualusa no decorrer da narrativa. O que poderia ser considerado mais insólito: uma osga narrar um romance, sonhar, se comunicar com humanos em sonhos (sendo que os humanos sonham concomitantemente com a osga em sua forma humana) ou se saber nomeada, Eulálio? Eulálio, apesar do nome assim determinar, não detém a capacidade do discurso, ao menos não acordado. O paradoxo do nome fornecido à lagartixa por Félix Ventura, Eulálio - de eulalia, ou a capacidade de pronunciar tudo com perfeita dicção - uma vez que a osga não falava, poderia reduzi-la às codificações do animal como propostas por Heiddeger e Benjamin. O discurso seria o que define o humano, e o animal seria destinado ao mutismo ao ser nomeado. $\mathrm{O}$ paradoxo de Eulálio, no entanto, se desfaz quando José Buchmann, a persona criada por Ventura para dar a Pedro Gouveia "um passado melhor", sonha com a osga ao mesmo tempo em que esta sonha com ele e, por meio do sonho, comunicam-se perfeitamente bem. Ou mesmo por meio da perfeita dicção com que Eulálio nos conta a história de Félix Ventura, o vendedor de passados, de José Buchmann e de Ângela Lúcia, a colecionadora de luzes, fazendo mesmo o leitor questionar a verdade da história que transborda as páginas do livro e colocar em xeque as suas próprias concepções.

$\mathrm{O}$ que em um primeiro momento poderia sugerir uma leitura alegórica, ou a classificação de fábula, uma vez que um animal narra, acaba por estraçalhar essas noções mesmas sugeridas pelas teorias da interpretação, dada a literalidade com que a osga se direciona a nós, leitores. Isso porque a leitura alegórica é submissa à recognição e impede a criação de outros mundos, pois a narrativa é subordinada a um real dado. Essas classificações são territorializações, assim como a leitura da condição do animal não-humano sempre em função do humano em seu pensamento codificado.

A osga pensa para narrar? "Eu penso" é uma territorialização, fixidez que aloca uma hierarquização de corpos. Quando dizemos “penso", fazemo-lo a partir de uma relação de forças que se estabeleceu como territó- rio. O que significa fazer parte desse território? É saber que se é racional, enquanto outros corpos não o são? Ou é estabelecer um poder sobre outros corpos, impedindo que eles executem sua potência de agir?

O sujeito do cogito cartesiano não pensa; ele tem apenas a possibilidade de pensar e se mantém estúpido no seio dessa possibilidade. Faltalhe a forma do determinável; não uma especificidade, não uma forma específica informando uma matéria, não uma memória informando um presente, mas a forma pura e vazia do tempo. É a forma vazia do tempo que introduz, que constitui a Diferença no pensamento, a partir da qual ele pensa, como diferença do indeterminado e da determinação. (DELEUZE, 2006, p. 382)

O tempo indeterminado dos "passados melhores" construídos pelo genealogista Félix Ventura permite que a experiência passada, assim como seu nome, seja uma aventura feliz. A memória, afinal, "é uma paisagem contemplada de um comboio em movimento" (AGUALUSA, 2015, p. 153), de modo que "tendemos a recordar como sendo nossas as recordações alheias, até mesmo as fictícias" (139). A realidade não é trivial, os absurdos a definem, pois alguns acontecimentos, conforme nos conta Eulálio, são muito improváveis para serem falsos. "A verdade é uma superstição" (75).

Da mesma maneira, Ludovica (AGUALUSA, 2012) cria seu espaço discursivo nas paredes do apartamento e constrói seu mundo metamorfoseando-se com ele, criando seu próprio tempo condensado, ao elaborar uma teoria geral do esquecimento:

Se ainda tivesse espaço, carvão e paredes disponíveis,

poderia escrever uma Teoria Geral do Esquecimento.

Dou-me conta de que transformei o apartamento inteiro num imenso livro. Depois de queimar a biblioteca, depois de eu morrer, ficará apenas a minha voz. Nesta casa todas as paredes têm a minha boca (AGUALUSA, 2012, p. 78). 
José Buchmann passa a metamorfosear-se também, como se matasse Pedro Gouveia (seu "eu" anterior), e o próprio Félix passa a acreditar em sua criação, como se vê nessa conversa com Ângela Lúcia:

- [...] Sei que tenho por vezes recordações falsas - todos temos, não é assim? os psicólogos ensinaram isso - mas penso que essa é verídica. - Acredito. Em contrapartida o teu amigo, o senhor José Buchmann, esse é completamente falso, certo? "inventaste-o tu...

Félix negou com veemência. Que não, pópilas!” que se fosse outra pessoa a dizer-lhe aquilo ele até poderia ficar ofendido, embora, pensando melhor, tal presunção devesse ser tomada por um elogio, pois só a própria realidade seria capaz de inventar uma figura tão inverossímil quanto José Buchmann.

- Eu, sempre que ouço falar em algo realmente impossível acredito logo. José Buchmann é impossível, não achas?, achamos os dois, então deve ser autêntico.

(AGUALUSA, 2015, p. 126)

Se Buchmann é autêntico, também o deve ser a osga-narradora, que deixa de ser "o outro": sai do lugar destinado aos animais pelos humanos e passa a ser não apenas uma personagem estranha na história, como o lagarto sorridente de rabo bifurcado de João Ubaldo Ribeiro, mas quem conta a história. José Buchmann, por sua vez, além de uma série de outras línguas, confessa a Eulálio em sonho que fala as línguas dos animais, tornando-se estrangeiro a si mesmo, à sua tradição e a quem era antes da metamorfose, Pedro Gouveia:

Disse-me também que falava inglês, nos seus diversos sotaques; falava também diversos dialectos alemães, o francês (de Paris) e o italiano. Garantiu-me que era capaz de discorrer com idêntica desenvoltura em árabe ou romeno. - Falo inclusive o blaterar -, ironizou: - a linguagem secreta dos camelos. Falo o arruar, como um javali nato. Falo o zunzum, o grilar e olhe, acredite, até o crocitar. Num jardim deserto seria capaz de discutir filosofia com as magnólias.

(AGUALUSA, 2015, p. 133)
Se em sonho Buchmann conversa com Eulálio de maneira clara e concisa, além de questionar a perspectiva de que o que diferenciaria os humanos de animais seria a linguagem, uma vez que ele falava línguas animais - e quiçá até das plantas -, todas as noções de superioridade humana em decorrência de uma capacidade de ação discursiva são colocadas em xeque pela narrativa. Eles inclusive sonham ao mesmo tempo, como se fosse um encontro entre amigos. Enquanto isso, a osga Eulálio produz o discurso narrativo do humano.

[O] estrangeiro se torna autóctone no outro que não o é, ao mesmo tempo que o autóctone se torna estrangeiro a si mesmo, a sua própria classe, a sua própria nação, a sua própria língua: nós falamos a mesma língua, e todavia eu não entendo você... (DELEUZE e GUATTARI, 2001, p. 142)

É uma paralaxe na perspectiva, que não apenas procura considerar e empatizar com "o outro", como parecem sugerir as teorias da alteridade, mas que traz à luz a perspectiva deste outro por deixá-lo falar em um espaço que era, até então, destinado apenas aos privilegiados, no caso, aos humanos, que narram suas histórias e as tocam com poesia desde os tempos imemoriais, mesmo antes da escrita como a concebemos hoje.

Essa voz animal que emerge e narra palavras humanas mesmo que pela escrita, uma vez que a osga apenas esboça como som estrondosas gargalhadas, expõe a perspectiva dos que sofreram e continuam a sofrer a violência epistêmica de uma relação de dominância que talvez seja ainda mais forte hoje porque emaranhada nos programas de verdade das sociedades que mantêm a lógica colonialista mascarada em seus sistemas de pensamento. A ideia de uma ética da alteridade, mesmo nos moldes de Lévinas, pressupõe o outro em função do pensamento etnocêntrico, por mais que se diga que ele, o outro, deva ter sua perspectiva respeitada. De que adianta ter sua perspectiva respeitada se sua voz continua apagada e seu nome continua sendo oferecido por aquele que crê dominar?

O narrador de Teoria geral do esquecimento, apesar de ser heterodiegético e não ceder a voz diretamente aos animais, apresenta a perspectiva da personagem 
Ludovica, cuja personalidade com tendências agorafóbicas a faz viver trancada em um apartamento com um pastor alemão albino nomeado por ela de Fantasma. Assim como o personagem Félix Ventura habita o espaço fechado e filosofa com a osga-tigre apesar de não ouvi-la além das gargalhadas, Ludovica torna-se uma outra no contato com Fantasma, e passa a se construir nas paredes do apartamento, produzindo narrativas a carvão, quando os papéis acabam.

O humano Félix Ventura, que se aventura na tentativa de burlar Chronos, o Deus escravizador convencionado como um programa de verdade no qual nossa tradição temporal se fixa, ao criar memórias antes inexistentes, duvida da própria história. Além disso, ele estabelece um estranhamento por ser como o cão Fantasma de Ludovica: albino. Outro no espaço outro. Ludovica, a humana que se tranca no apartamento localizado no último andar do Prédio dos Invejados em uma Luanda em plena guerra de independência, escreve seus processos de sujeição, subjetivação e posteriores desterritorializações nas paredes do apartamento, como a lagartixa o faz nas páginas do livro. Eulálio se sonha humano, Ludovica se sonha animais, em devires anômalos que não seguem os codificados processos de filiação:

Hoje não aconteceu nada. Dormi. Dormindo sonhei que dormia. Árvores, bichos, uma profusão de insetos. Ali estávamos todos, sonhando em coro, como uma multidão, num quarto minúsculo, trocando ideias e cheiros e carícias. Lembro-me que fui uma aranha avançando contra a presa e a mosca presa na teia dessa aranha. Senti-me flores desabrochando ao sol, brisas carregando pólenes.

(AGUALUSA, 2012, p. 33)

Enquanto Ludo se compõe e constrói no decorrer de suas sequências animais em sonhos e fora deles, Eulálio também sonha com humanos e animais em fusão, que o fazem questionar a verossimilhança da realidade em comparação aos seus sonhos:

Depois o cão se afastou, mancando um pouco, e tudo voltou a ficar em silêncio. Saltei o muro e fui-me embora, em direção às luzes da cidade. Antes de alcançar a estrada ainda vi o ra- paz, rente ao muro, abraçado ao perdigueiro. Olhavam para mim, os dois, como se fossem um único ser. Voltei-lhes as costas mas continuei a sentir (como se alguma coisa escura me batesse por trás) o olhar desafiador do cão e do menino. Acordei em sobressalto. Estava numa fenda úmida. Formigas pastavam entre meus dedos. Fui à procura da noite. Os meus sonhos são, quase sempre, mais verossímeis do que a realidade. (AGUALUSA, 2015, p. 50)

Em um segundo momento, seus próprios sonhos passam a compor a realidade, como se ele se comunicasse com Félix Ventura e José Buchmann enquanto assumia forma humana no sonho: "Contou-me, na última vez que nos sonhamos, o caso de um amigo [...]" (AGUALUSA, 2015, p. 145).

Os devires animais dos humanos de Agualusa transbordam as páginas do livro e as paredes do apartamento em sequências de estranhamento que nos aproximam, nós, humanos, que achamos que pensamos, logo existimos, das tristes palavras vocalizadas pelos animais da ilha do Dr. Moreau, animais territorializados física e epistemologicamente pelos polegares opositores e pela fala aparentemente coesa do médico-humano que forja uma humanidade nos animais. Assim como nós, quando nomeamos nossos pequenos espelhos narcísicos chamados bichos de estimação, animais territorializados que vestem sapatos, buscando arrancar deles uma condição humana que é, em verdade, nossa. E não buscamos o animal que logo somos, que logo seguimos, uma vez que nossa tendência é sempre nomear o outro e esperar que ele aja em função de nós, nunca o contrário. Afinal, acreditamos que pela nossa capacidade de criar objetos tecnológicos e de nos comunicarmos de modo supostamente coeso podemos dominar "o outro", assim como o enxergamos, fazendo com que ele, o outro em relação a nós, tenha sua vida reduzida a ações em função de nosso poder de dominação.

Todavia, Agualusa nos mostra, ao contrário de Moreau, as irresistíveis e inauditas sequências animais pelas quais Ludovica passa e escancara a perspectiva da osga-tigre gargalhando de Félix Ventura, como o lagarto de dois rabos zombou de João Pedroso por sua prepotência ao pensar que pensava, e que isso seria suficiente para afirmar uma existência. 
Ludovica se escreve nas paredes do apartamento depois de devir uma tartaruga bebê sem casco, absolutamente vulnerável, com um mar aberto à frente. $\mathrm{O}$ apartamento se constrói como uma concha, concha de ostra, junto à personagem. O animal que logo é, que logo segue, ostra, cisma:

\author{
eu ostra cismo \\ cá com minhas pérolas
}

cacos no abismo

(NÓVOA ${ }^{1}$ / AGUALUSA, 2012, p. 67)

Mas não conclui que existe. Diz: "Eu ostra cismo". Ela é ostra, se escreve e inscreve na própria concha um ostracismo, um afastamento. Permite que suas sequências animais a-significantes fluam: tartaruga sem casco, ostra, cão, macaco. Ainda que cisme, não pressupõe que existe, afinal a cisma é apenas um entre muitos mundos.

A osga é nomeada, assim como o cachorro. Eulálio e Fantasma. No entanto, nada têm de embrutecimento, como sugeriria Heidegger. A osga narra a história de todos, e Fantasma relembra Ludovica do animal que ela logo é. Animot, animal-palavra, ânima. Pois quebram a perspectiva da superioridade humana e desconsideram nossa precipitação em afirmar que o animal não fala. $\mathrm{Ou}$, como sugere Derrida em sua leitura do texto de Carroll, que o animal não responde, ou que responde sempre a mesma coisa. Alice é bastante cartesiana no final das contas.

Precipitamo-nos em afirmar o não-pensamento e o não-discurso animal porque ignoramos nossa porção bestial e acreditamos, como Descartes, que o mundo é efetivamente da maneira como o organizamos epistemologicamente, racionalmente. Quem, organizamos? Há apenas uma maneira de entender o mundo e conceber os estados de coisas? Hume já dizia, no século XVIII, que as operações cognitivas que atribuem causas aos acontecimentos são apenas isso: operações cognitivas. Precipitamo-nos também em crer que nossas operações cognitivas compreendem os estados de coisas tais como eles são, não pensamos que talvez os tenhamos construído dessa maneira, graças às próprias operações cognitivas, às nossas cismas, que ignoram as ostras, os cães e as osgas em nós.

Enquanto Dr. Moreau manipulava tecnologicamente, medicamente, os animais com o intuito de reduzi-los às codificações humanas por meio da técnica cirúrgica da vivissecção, impondo-lhes o sofrimento das territorializações (a vida humana acima de qualquer coisa, prevê nosso programa de verdade científico), Ludovica devém um outro, quando em contato com o revolucionário macaco nomeado por ela de Che Guevara. $\mathrm{O}$ assassinato do outro que Ludo logo segue, um outro que Ludo logo é, para tirá-lo de seu sofrimento e comê-lo, no dia seguinte, numa espécie de metafísica canibal, absorvendo o animal que ela logo é, que logo somos, que logo seguimos, nomeados, como eles foram por nós, ao nascer. Afinal de contas, não somos nós também nomeados? Nomes que nos são dados e que, como disse a osga Eulálio, podem ser uma condenação:

\begin{abstract}
Alguns arrastam o nomeado, como as águas lamacentas de um rio após as grandes chuvadas, e, por mais que resista, impõem-lhe um destino. Outros, pelo contrário, são como máscaras: escondem, iludem. A maioria, evidentemente, não tem poder algum. Recordo sem prazer, sem dor também, meu nome humano. Não lhe sinto a falta. Não era eu.

(AGUALUSA, 2012, p. 44)
\end{abstract}

A nomeação é uma territorialização. Nomeamos nossos bichos de estimação que supostamente não podem nomear a si próprios, mas somos, nós mesmos, nomeados. Destinados ao nascer ao território do humano, de sermos algo codificado pelas palavras, e achamos, desta forma, que podemos codificar o outro, aquele outro que não se nomeia, mas que não se precipita em dizer que pensa, logo existe, mas pode nos lançar sorrisos e gargalhadas zombeteiras por assim pensarmos, assim como fez a osga filósofa ao genealogista Félix Ventura. Ou ainda aparecer-nos em sonho e fazer-nos questionar nossa própria sanidade, como acontece a Ludovica: "Acordei e estava sozinha. Se, dormindo, sonhamos dormir, podemos, despertos, acordar dentro de uma realidade mais lúcida?" (AGUALUSA, 2015, p. 33). 
Ludovica estabelece uma relação animal que quebra com as noções preestabelecidas pelos agenciamentos de poder do mundo fora de sua concha também com o cão Fantasma. Constrói-se quase um mise en abyme de linhas de fuga, uma dentro da outra, como quando se depara com o animal que logo é:

Alimentou Fantasma a papas de farinha de trigo. As noites fundiam-se com os dias. Acordava e via o cão a vigiá-la numa feroz ansiedade. Adormecia e sentia-lhe o bafo ardente. Foi à cozinha procurar uma faca, a de lâmina mais longa, a mais afiada, e passou a trazê-la presa à cintura, como uma espada. Também ela se debruçava sobre o sono do animal. Várias vezes lhe encostou a faca ao pescoço.

(AGUALUSA, 2012, p. 37).

A personagem flui em um vertiginoso devir-cão, fluxos que a atravessam na composição com Fantasma; é habitada por matilhas que rosnam pelo alimento e uivam dores lancinantes com o macaco esfaqueado, o macaco revolucionário, Che Guevara, nomeado também por Ludovica. Mas como sugeriu Eulálio, "ninguém é um nome". Eulálio aceita seu nome de "verbo fácil":

- Não -, confirmou [Félix] num sopro: - Não sei quem é. Mas se sou eu quem o sonho posso dar-lhe o nome que quiser, não achas?, vou chamá-lo Eulálio, porque tem o verbo fácil. Eulálio? Pareceu-me bem. Serei pois Eulálio. (AGUALUSA, 2012, p. 89)

Eulálio aceita seu nome, enquanto Ludo recusa sua roupagem humana: devém tartaruga sem casco, abrindo espaço na areia como um bebê tartaruga que é puro devir e se arrasta ao mar, uma imensidão que se abre, sem território fixo, a sua frente. Cria um novo casco, uma concha, num protetor devir-ostra que produz singulares corpos estranhos dentro de si, pérolas encravadas na parede, narrativas escritas com toda a intensidade do seu não-ser.

A osga filosofa sobre o tempo em que era humana. $\mathrm{O}$ único passado que não pode ser mudado, segundo ela, é o passado humano. Mas Félix Ventura subverte essa estrutura e reconstrói a vida passada do estrangeiro agora angolano José Buchmann, que por sua vez sofre a metamorfose, como se, fechado em uma crisálida, sofresse o "secreto alvoroço das enzimas dissolvendo os órgãos" (Agualusa 2012: 59).

Apressamo-nos em interpretar uma narrativa classificando-a como fábula, pois nos precipitamos, como Alice, a dizer que um animal não fala, não responde, ou responde sempre a mesma coisa. Dizemos que é uma metáfora, uma alegoria, ou que o animal representa um humano, porque não suportamos ter as categorias nas quais nos inscrevemos, oriundas do racionalismo de matriz cartesiana, questionadas pelas narrativas.

Podemos dizer que a obra de Agualusa flerta com uma concepção que desconstrói a antiga máxima Aristotélica de que "poesia é imitação". Para Aristóteles (1984), a "poesia como imitação" tornaria o poeta um fingidor na medida em que este imitaria, nos versos, uma realidade possível, lançando mão de recursos para manter a verossimilhança. Contudo, na contemporânea narrativa de Agualusa, o questionamento não recai mais sobre uma suposta imitação da qual a poesia seria o meio, mas sobre o próprio estatuto da realidade e da verossimilhança. Não é um questionamento platônico, antes o contrário: não há mundo ideal, a realidade é questionada não por ser ela própria uma cópia imperfeita, como sugeririam os neoplatônicos, mas por ser uma criação, assim como a poesia. Sendo uma criação, é apenas a imanência de uma possibilidade entre inúmeras. A própria realidade é uma ficção e a ficção pode, ela própria, devir realidade. Isso já nos dizia Borges (1986).

Desta forma, quando falamos que o poeta é um fingidor, damo-lo o status de produtor de realidade, uma vez que a realidade é uma ficção e a ficção narrada pelo poeta devém realidade. Félix Ventura é o poeta de passados; cria "um passado melhor" para aqueles que desejam elaborar sua própria teoria geral do esquecimento à maneira de Zaratustra (Nietzsche 2011) ou de Ludovica. Enquanto Eulálio, com sua perfeita dicção de pensamento, eulalia, cria a narrativa que nos é contada: o falar com animais de José Buchmann (que tem as mesmas iniciais de Borges, diga-se de passagem), a coleção de luzes do anjo lúcido Ângela Lúcia e as incontáveis aventuras felizes das narrativas de Félix Ventura. Eulálio é, afinal, uma osga. Um animot, animal palavra. 
Não é nomeado como propõe Benjamin, tampouco sofre o embrutecimento heideggeriano, mas, ao contrário, poetiza em narração ao contar a história, pensamento tornado narrativa, sonho tornado realidade, assim como Ludovica torna-se, ela mesma, as paredes de seu apartamento rabiscadas de poesia. Escritura tornada vida. Afinal, se o pensamento do animal, se pensamento houver - como sugeriu Derrida - cabe à poesia, cabe perfeitamente bem a esta Zoo(po)ética de Agualusa.

\section{Nota}

1. O poema foi escrito pela brasileira Christiana Nóvoa, a pedido de Agualusa.

\section{Referências}

AGUALUSA, José Eduardo. O vendedor de passados. $3^{\mathrm{a}}$ edição. Rio de Janeiro, Gryphus, 2015.

AGUALUSA, José Eduardo. Teoria geral do Esquecimento. Rio de Janeiro: Foz, 2012.

ARISTÓTELES. Poética. Pensadores. São Paulo: Abril, 1984.

BENJAMIN, Walter. Escritos sobre mito e linguagem (1915-1921). Tradução: Susana Kampff Lages e Ernani Chaves. São Paulo: Duas Cidades; Editora 34, 2011.

BORGES, Jorge Luis. 1986. Ficciones: relatos. Barcelona: Seix Barral.

DELEUZE, Gilles e GUATTARI, Felix. O que é a filosofia?. Tradução: Alberto Alonso Muñoz e Bento Prado Jr. São Paulo: 34, 2001.

Mil Platôs - Capitalismo e Esquizofrenia - Vol 4. Tradução: Suely Rolnik. São Paulo: 34, 2012.

DELEUZE, Gilles. Diferença e Repetição.Tradução: João Orlandi e Roberto Machado. Rio de Janeiro: Graal, 2006.

DERRIDA, Jacques. O animal que logo sou (A seguir). Tradução: Fábio Landa. São Paulo: Editora Unesp, 2002.

HARAWAY, Donna. Manifesto ciborgue: Ciência, tecnologia e feminismo-socialista no final do século XX. In: Tomaz Tadeu (org). Antropologia do ciborgue: As vertigens do pós-humano. Belo Horizonte: Autêntica, 2009. pp. 33-118.

HEIDEGGER, Martin. The fundamental concepts of metaphysics. Tradução: William McNeill e Nicholas Walker. Bloomington: Indiana University Press, 1995.
NIETZSCHE, Friedrich Wilhelm. Assim falou Zaratustra: um livro para todos e para ninguém. Tradução: Paulo César de Souza. São Paulo: Companhia das Letras, 2011.

PAZ, Octávio. O arco e a lira. Tradução: Paulina Wacht e Ari Roitman. São Paulo: Cosac Naify, 2014.

RIBEIRO, João Ubaldo. O sorriso do Lagarto. Rio de Janeiro: Nova fronteira, 1989.

WELLS, Herbert George. The Island of Doctor Moreau (1896). Disponível no Projeto Gutemberg: http://www. gutenberg.org/files/159/159-h/159-h.htm. Acesso em 12 out 2015. Project Gutemberg, 2012.

Recebido em: 12/11/2016 Aceito em: 25/02/2017 